\title{
Reliability Assessment of Nigerian Power Systems Case Study of 330kv Transmission Lines in Benin Sub - Region
}

\author{
S. O. Okozi ${ }^{1}$, P.C Chukwudi ${ }^{2}$, M. Olubiwe ${ }^{3}$ and K.C Obute ${ }^{4}$ \\ 1, 2, 3, ----Dept. Of Electrical/Electronic Engineering, Federal Univ. Of Technology Owerri, Nigeria \\ 4, ......Dept. Of Electrical Engineering, Nnamdi Azikiwe University Awka, Nigeria.
}

\begin{abstract}
The need for stable electricity supply in Nigeria cannot be overemphasized as it is a pre-requisite to economic, social and technical development. The consequences of interruption of supply in the transmission system is considerably high because an outage event in the transmission system can propagate and paralyze a widespread geographical area. This research is based on the reliability analysis of the existing $330 \mathrm{kV}$ transmission lines in Benin sub - region. The system downtimes, failure rate, duration of repairs were evaluated. The collected data were analyzed mathematically to estimate the reliability of the network and reliability indices computed for each line. The results reveals the weakness of the system in the frequent failures that occurred on six out of the thirteen circuit breakers of the work Centre and the poor maintenance of the others.
\end{abstract}

Keywords: Reliability, Availability, Reliability Indices, Benin, failure rate.

\section{INTRODUCTION}

Reliability in Power system is a measure of how consistent a network is after series of interruptions. Reliability is an important topic that cuts across all disciplines of engineering but record has it that equipment reliability problems which occurred during the Second World War triggered the development of reliability studies [1]. As the use of electricity increases, the chances of power failures also increases. It is therefore very important to carry out a proper reliability study of the network for proper planning and operation of a power systems.

Reliability may be defined in many ways for any system. This is true for electric power systems in general and the transmission system in particular [2]. Power system reliability is the probability that an electric power system can perform a required function satisfactorily under given conditions for a given time interval [3]. This quantifies the ability of an electric power system to supply adequate electric service on a nearly continuous basis with few interruptions over an extended period of time [4]. The degree of reliability may be measured by the frequency, duration, and magnitude of adverse effects on consumer service.

As the reliability of electric supply is directly associated with the quality of life in modern society, the importance of supplying highly reliable electric energy cannot be overemphasized [3]. Therefore, electric utilities are saddled with the responsibility to supply its customers with electric power with an acceptable degree of quality and continuity at the lowest possible cost.

Currently, electric power throughout the world is undergoing considerable changes due to the converging forces of deregulation, technological revolution and evolving customer expectations [5]. Hence the need for rigorous and quantitative reliability analysis. Reliability concerns are often split into three categories: adequacy; the capacity to meet demand, security; the ability to survive imminent disturbances, and quality; frequency, voltage and harmonic characteristics.

A power system is designed to perform its function not for a limited short period but for a relatively long time. Failures can occur at different points in the system at certain times, but these failures can always be repaired, and the system can be constantly developed in order to satisfy the changing demands and to improve the performance of its function. It is therefore important for a power system operator to recognize and control the various possible system failures and to minimize the failure effects that the customer experiences [6]. One definition of system reliability is simply the control of failures. The measurement of power system reliability includes the unavailability, the expected failure frequency and duration, and the expected magnitude of adverse effects on consumer service.

By the pattern of life and activities in modern societies, the objective of any electrical utility is to ensure that the customer is satisfied at a reliable level of performance. This calls for high reliability of its component parts and its operation. However, because of the size and complexity of an average sized Power Systems, an assessment of complete power system as a unit is not recommended. In practice therefore, the reliability assessment of a power system is carried out by separately investigating the reliabilities of its different stages or sub-systems. Therefore, this work is based on the reliability assessment of $330 \mathrm{kV}$ transmission lines in Benin sub-region. The Benin $330 \mathrm{kV}$ substation is at the centre of power evacuation in Nigeria, hence very important in the analysis of Nigerian Power Systems.

The bulk electric power is typically transferred through the transmission system over long distances at high voltage levels from the generating stations to major load centres. The consequences of interruption of supply in the transmission system is considerably high because an outage event in the 
transmission system can propagate and paralyze a widespread geographical area. Thus the need to mitigate the effect of faults by reducing the system downtimes and ensure reliable services to consumers.

\section{RELIABILITY INDICES}

Reliability is a probability expression which needs to be quantified to make it suitable for scientific analysis. The quantification is done by introducing -performance parameters which indicate the degree of reliability and are called indices of reliability. Some of them are explained below.

(A.) FAILURE RATE $(\lambda)$ : It is a measure of the frequency at which faults occurs. Two definitions of failure rate are available, depending on whether it relates to repairable or non-repairable items. The definition which relates to non-repairable items expresses failure rate as a percentage and is given by:

$$
\text { FAILURE RATE }(\lambda)=\frac{F A U L T F R E Q U E N C Y}{\text { PERIOD OF OCCURRENCE }}
$$

The other definition relates to repairable items or systems and expresses failure rate as the number of failures which occurs per unit-hour of operation. It is denoted by $\lambda(\mathrm{N})$ and given as:

\section{FAILURE RATE $(\lambda)$ $=\frac{\text { NUMBER OF TIMES FAILURE OCCURED }}{\text { NUMBER OF UNIT HOUR OF OPERATION }}$}

The unit of $\lambda$ is therefore failures per unit-hour. Obviously, a high value of $\lambda$ is indicative of low reliability.

(B.) MEAN TIME TO REPAIR (MTTR) OR MEAN DOWN TIME (MDT): This is the average time that is needed to restore a system or an item to operational effectiveness once it fails. MTTR is a function of equipment design, the expertise of the personnel and the tools available.

$$
\begin{aligned}
& \text { MDT } \\
& =\frac{\text { TOTAL DURATION OF OUTAGES }}{\text { FREQUENCY OF OUTAGE }}
\end{aligned}
$$

Clearly a low value of MTTR indicates good maintainability.

(C.) MEAN TIME BETWEEN FAILURES (MTBF): This is another index of reliability. It expresses the average time, which elapses between consecutive failures of a repairable system of equipment. Mathematically, MTBF is given by:

$$
M T B F=\frac{\text { TOTAL SYSTEM OPERATING HOURS }}{\text { NUMBER OF FAILURES }}
$$

Clearly the longer MTBF is, the more reliable is the system.

(D.) AVAILABILITY (A): This is an important basic index of reliability. It is the probability that equipment will be available to perform as required or that it will be in a state of operational effectiveness within a given period. Mathematically, Availability (A) is given as:

Availability $(A)=\frac{M T B F-M T T R}{M T T R}$

\section{RELIABILITY EVALUATION}

The reliability evaluation helps to determine whether an existing Power Systems is consistent in its operation. They are used for measuring or evaluating reliability of power distribution system based on observed outage data for a set of loads, customers, feeders, territories and so on.

Reliability evaluation requires data on the number of interruptions on the system, outage duration, and number of affected consumers. These indices include;

(i) Average System Availability Index (ASAI)

This is the percentage of time that a customer has received power during the reporting period.

$$
\text { ASAI }
$$

$$
\frac{\text { CUSTOMER HOURS SERVICE AVAILABILITY }}{\text { CUSTOMER HOURS SERVICE DEMANDS }}
$$

It is a measure of the overall reliability of the system.

$$
A S A I=\left[1-\frac{\Sigma\left(t_{i} N_{i}\right)}{N_{T} T}\right] * 100
$$

(ii) Customer Average Interruption Duration Index (CAIDI)

CAIDI is the average time needed to restore service to an average customer after interruption. The average duration of interruptions per customer that had an interruption or simply the average time to restore service after interruptions.

CAIDI

TOTAL DURATIONS OF INTERUPTIONS TOTAL NUMBER OF CUSTOMERS INTERRUPTED

(3)

$$
C A I D I=\frac{\sum\left(t_{i} N_{i}\right)}{N_{I}}
$$

(iii) System Average Interruption Duration Index (SAIDI)

SAIDI is the most used index for measuring reliability of a system. It measures length of time an average customer is on blackout. It is given by;

$$
\text { SAIDI }=\frac{\text { DURATION S FOR CUSTOMER INTERRUPTION }}{\text { TOTAL NUMBER OF CUSTOMERS UNDER CONSIDERATION }}
$$




$$
S A I D I=\frac{\sum\left(t_{i} N_{i}\right)}{N_{T}}
$$

(iii) System Average Interruption Frequency Index (SAIFI) SAIFI is a measure of how often an average customer experiences a sustained interruption.

$S A I F I=$ TOTAL NUMBER OF CUSTOMERS INTERRUPTED TOT AL NUMBER OF CUSTOMER UNDER CONSIDERATION

\section{METHODOLOGY}

System reliability evaluation is based on reliability data for the items which make up the system. The collection of system component reliability data is therefore a fundamental task in system reliability evaluation. Many electric power utilities have traditionally recorded the performance of power system components. These recordings are the primary sources of the component reliability data required for the purpose of conducting power system reliability evaluation.
Benin sub-region has nineteen (19) $330 \mathrm{kV}$ lines connected to the National grid cutting across four work Centres with a total of $1,321.62 \mathrm{~km}$ transmission distance. But as earlier stated in the limitations only thirteen (13) circuits/lines having a total of $1059.3 \mathrm{~km}$ transmission distance will be reflected in this work. The various circuits and their transmission length are shown on Table 1. The work centres are: Benin work Centre, Ajaokuta work Centre, Sapele work entre and Delta work centres.

Having reviewed different techniques adopted by various authors in Reliability Engineering [1], it is clear that mathematical techniques can be used for quantifying reliability (prediction and measurement) and analyzing reliability data. Although the role of mathematical techniques in reliability engineering is limited. This technique predicts the reliability of a complex system based on its structure and the reliability of each component including the assumption that all the failures are independent and that the rate of failure is constant.

TABLE 1: 330KV TRANSMISSION LINES DISTANCE CHART IN BENIN REGION

\begin{tabular}{|c|c|c|c|c|}
\hline $\mathrm{S} / \mathrm{N}$ & NAME/CIRCUIT & TOWER NUMBER & $\begin{array}{l}\text { LENGTH OF SPANS } \\
\text { (M) }\end{array}$ & $\begin{array}{l}\text { TOTAL } \\
\text { LENGTH }\end{array}$ \\
\hline 1 & Benin/Onitsha 330KV Line 1 (B1T) & T1-175 & $392.55 \mathrm{M}$ & $68.2 \mathrm{KM}$ \\
\hline 2 & Benin/Onitsha 330KV Line 2 (B2T) & T1-175 & $392.55 \mathrm{M}$ & $68.2 \mathrm{KM}$ \\
\hline 3 & Benin/Egbin 330KV Line (B6N) & T1-250 & $371.87 \mathrm{M}$ & $92.4 \mathrm{KM}$ \\
\hline 4 & Benin/Omotosho 330KV Line (B5M) & T1-250 & $338.39 \mathrm{M}$ & $84.1 \mathrm{KM}$ \\
\hline 5 & Ihovbor/Oshogbo 330KV Line (V7H) & T1-53,442-371 & $485.8 \mathrm{M}$ & $59.7 \mathrm{KM}$ \\
\hline 6 & Ihovbor/Benin 330KV Line (V7B) & T1-53,442-505 & $350.88 \mathrm{M}$ & $40.3 \mathrm{KM}$ \\
\hline 7 & Benin/Ajaokuta 330KV Line 1(B11J) & T1-446 & $438.2 \mathrm{M}$ & $194.9 \mathrm{KM}$ \\
\hline 8 & Benin/Ajaokuta 330KV Line 2 (B12J) & T1-446 & $438.2 \mathrm{M}$ & $194.9 \mathrm{KM}$ \\
\hline 9 & Sapele/Benin 330KV Line 1 (S3B) & T1-118 & $427.35 \mathrm{M}$ & $49.9 \mathrm{KM}$ \\
\hline 10 & Sapele/Benin 330KV Line 2 (S4B) & T1-118 & $427.35 \mathrm{M}$ & $49.9 \mathrm{KM}$ \\
\hline 11 & Sapele/Benin 330KV Line 3 (S5B) & T1-119 & $427.35 \mathrm{M}$ & $50.4 \mathrm{KM}$ \\
\hline 12 & Delta/Benin 330KV Line 1 (G3B) & T1-119 & $406.85 \mathrm{M}$ & $47.9 \mathrm{KM}$ \\
\hline 13 & Delta/Sapele 330KV Line 2 (S4G) & T1-145 & $406.85 \mathrm{M}$ & $58.5 \mathrm{KM}$ \\
\hline
\end{tabular}

The results of the reliability evaluation are normally indices that represent the reliability of the system. Generally, these reliability indices describe the system ability to supply electric energy to the load points in the system. The indices can be defined either for separate load points or for the overall system as applied here. 
TABLE 2: SUMMARY OF ANNUAL FREQUENCY AND DURATION OF OUTAGES ON THE 13 CIRCUITS OF BENIN WORK CENTRES

\begin{tabular}{|c|c|c|c|c|c|c|}
\hline \multirow[b]{2}{*}{ MONTH(S) } & \multicolumn{2}{|c|}{ SCHEDULED OUTAGE } & \multicolumn{2}{|c|}{ FORCED OUTAGE } & \multicolumn{2}{|c|}{ TOTAL OUTAGE } \\
\hline & FREQ. & $\begin{array}{l}\text { DURATION } \\
{[\text { HRS }]}\end{array}$ & FREQ. & $\begin{array}{l}\text { DURATION } \\
\text { [HRS] }\end{array}$ & FREQ & $\begin{array}{l}\text { DURATION } \\
\text { [HRS] }\end{array}$ \\
\hline G3B & 6.00 & 48.96 & 22.00 & 28.53 & 28.00 & 77.49 \\
\hline B1T & 2.00 & 24.73 & 16.00 & 145.59 & 18.00 & 203.38 \\
\hline B2T & 8.00 & 32.14 & 17.00 & 51.62 & 25.00 & 83.76 \\
\hline B6N & 11.00 & 110.61 & 48.00 & 336.01 & 59.00 & 446.62 \\
\hline B5M & 14.00 & 89.65 & 20.00 & 77.53 & 34.00 & 167.18 \\
\hline B11J & 16.00 & 105.30 & 34.00 & 202.84 & 50.00 & 308.14 \\
\hline B12J & 8.00 & 40.62 & 29.00 & 71.57 & 37.00 & 112.19 \\
\hline V7H & 9.00 & 44.67 & 36.00 & 107.64 & 45.00 & 151.23 \\
\hline V7B & 12.00 & 54.37 & 34.00 & 39.41 & 46.00 & 94.78 \\
\hline S3B & 9.00 & 22.15 & 20.00 & 53.00 & 29.00 & 75.15 \\
\hline S5B & 8.00 & 41.20 & 24.00 & 77.65 & 32.00 & 118.85 \\
\hline S4B & 13.00 & 41.85 & 30.00 & 393.47 & 43.00 & 435.32 \\
\hline S4G & 16.00 & 30.91 & 18.00 & 318.97 & 34.00 & 349.88 \\
\hline TOTAL & 132.00 & 687.16 & 348.00 & 1903.76 & 480.00 & 2623.97 \\
\hline
\end{tabular}

Having reviewed different techniques adopted by various authors in Reliability Engineering [7], it is clear that mathematical techniques can be used for quantifying reliability (prediction and measurement) and analyzing reliability data. This technique predicts the reliability of a complex system based on its structure and the reliability of each component including the assumption that all the failures are independent and that the rate of failure is constant.

The results of the reliability evaluation are normally indices that represent the reliability of the system. The indices can be defined either for separate load points or for the overall system and for the overall system as in this case, the reliability is based on availability, failure rate, MTBF and MDT for the different Circuit Breakers (CB) are shown in Figs 1-13.

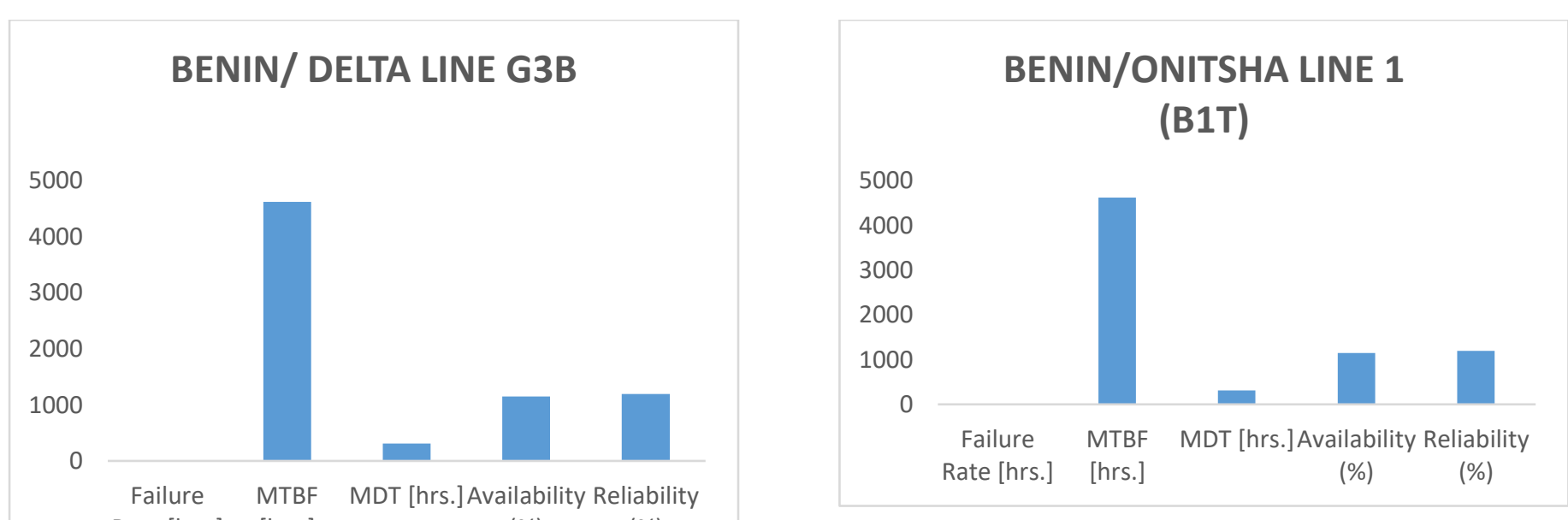

Rate [hrs.] [hrs.] (\%) (\%)

Fig. 2 Reliability Indices for B1T

Fig. 1: Reliability Indices for G3B 


\section{BENIN/ONISTHA LINE 2 (B2T)}

5000

4500

4000

3500

3000

2500

2000

1500

1000

500

0

Failure MTBF MDT [hrs.] Availability Reliability Rate [hrs.] [hrs.]

(\%)

(\%)

Fig. 3: Reliability Indices for B2T

\section{BENIN/EGBIN LINE (B6N)}

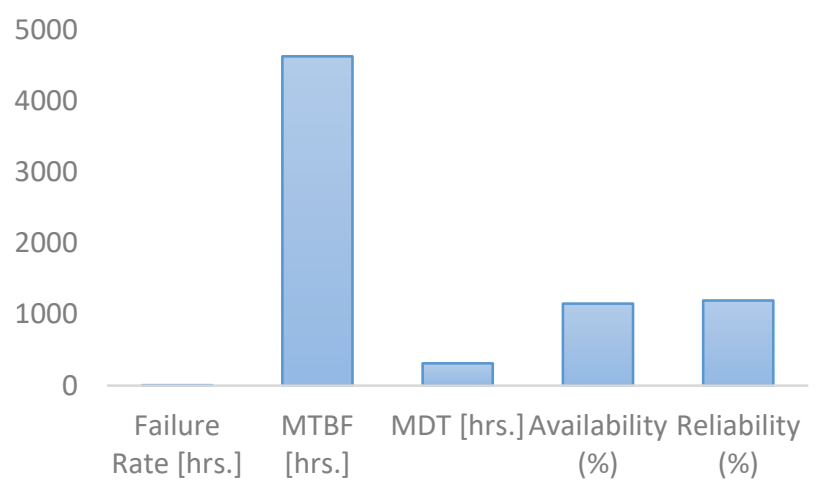

Fig. 4: Reliability Indices for B6N

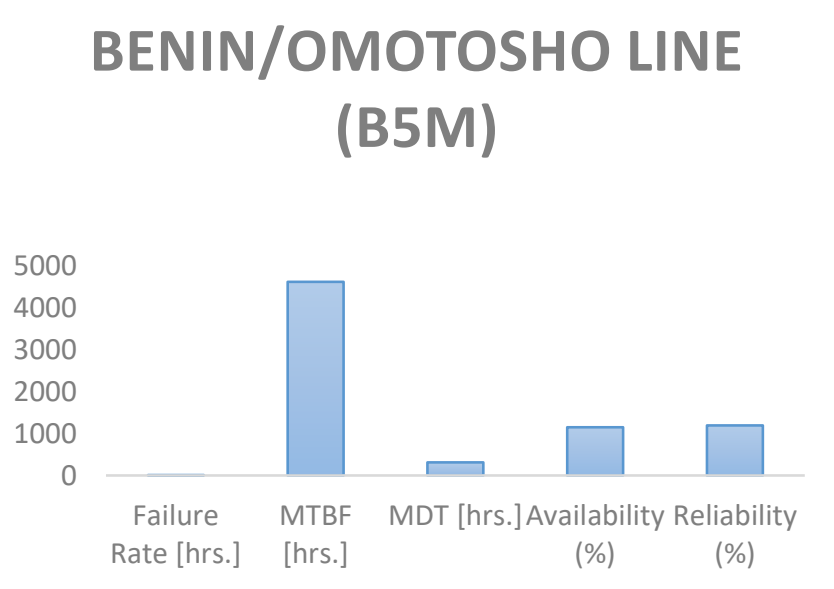

Fig. 5: Reliability Indices for B5m

\section{BENIN/AJAOKUTA LINE 1} (B11J)

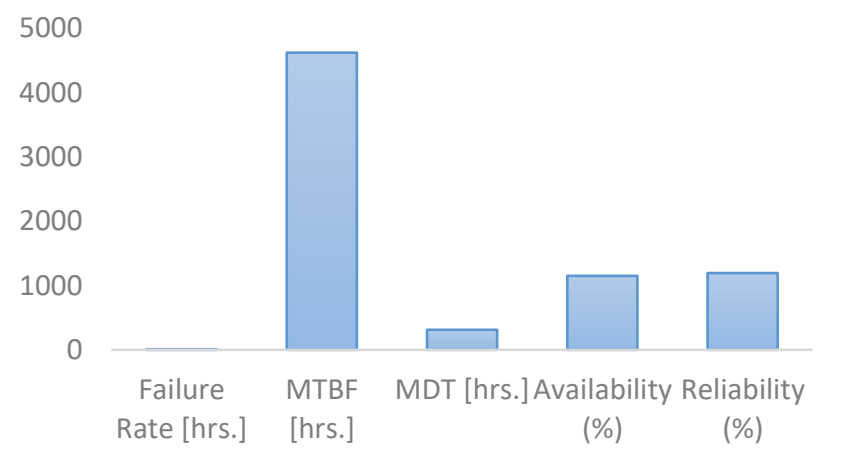

Fig. 6: Reliability Indices for B11J

\section{BENIN/AJAOKUTA LINE 2} (B12J)

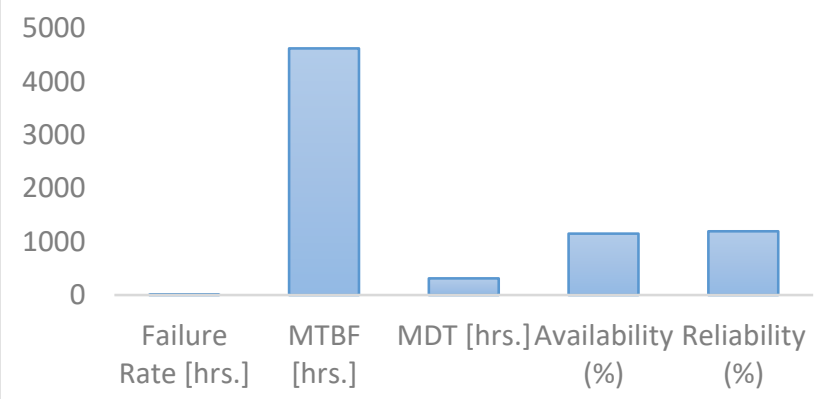

Fig. 7: Reliability Indices for B12J

\section{IHOVBOR/OSHOGBO LINE (V7H)}

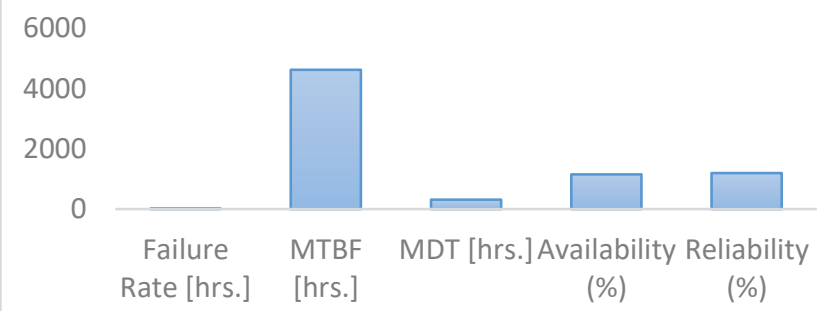

Fig.8: Reliability Indices for V7H 


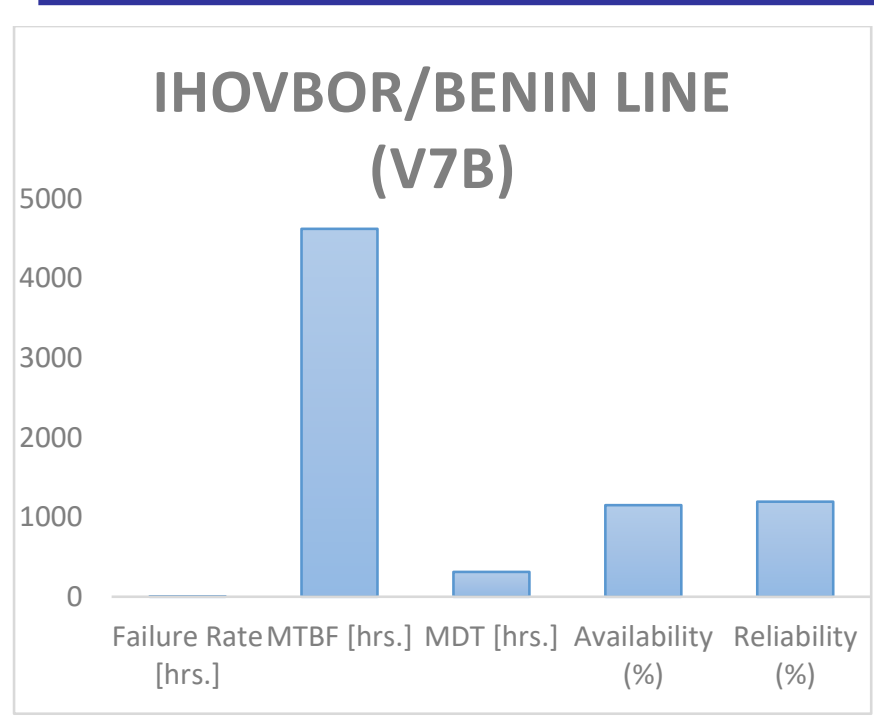

Fig. 9: Reliability Indices for V7B

\section{SAPELE/BENIN LINE 1 (S3B)}

5000

4500

4000

3500

3000

2500

2000

1500

1000

500

0

Failure MTBF MDT [hrs.] Availability Reliability
Rate [hrs.] [hrs.]
(\%)
(\%)

Fig. 10: Reliability Indices for S3B

\section{SAPELE/BENIN LINE 2 (S4B)}

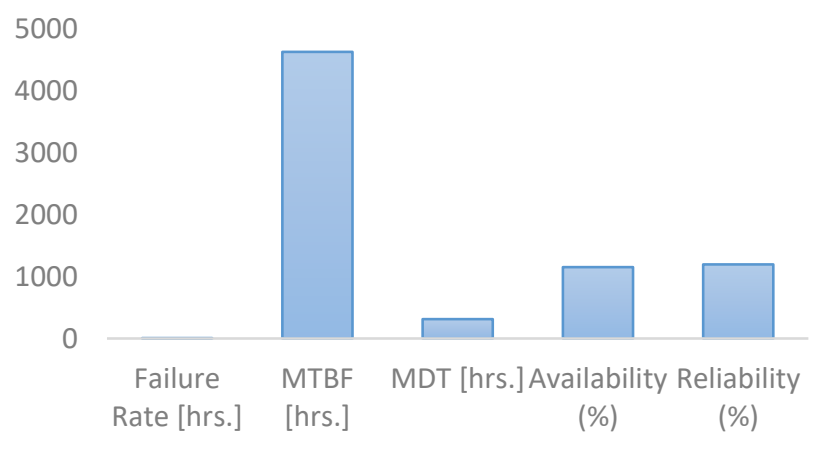

Fig. 11: Reliability Indices for S4B

\section{SAPELE/BENIN LINE 3 (S5B)}

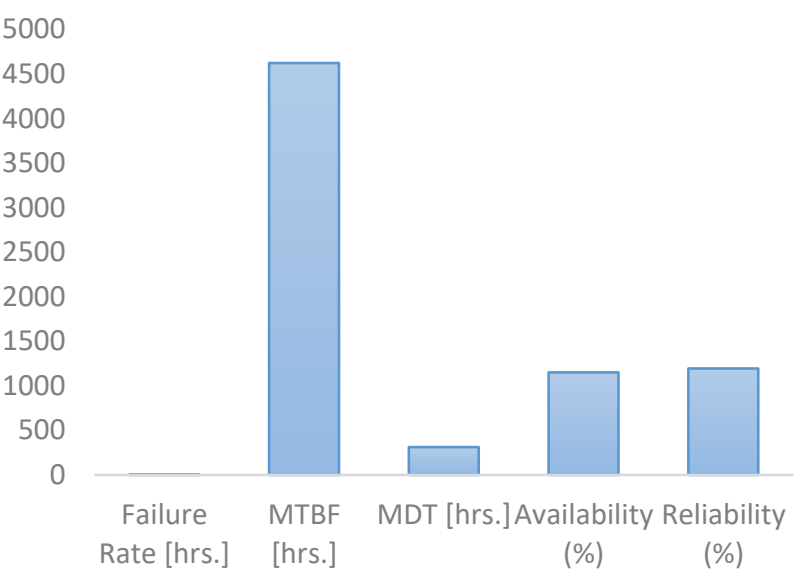

Fig. 12: Reliability Indices for S5B

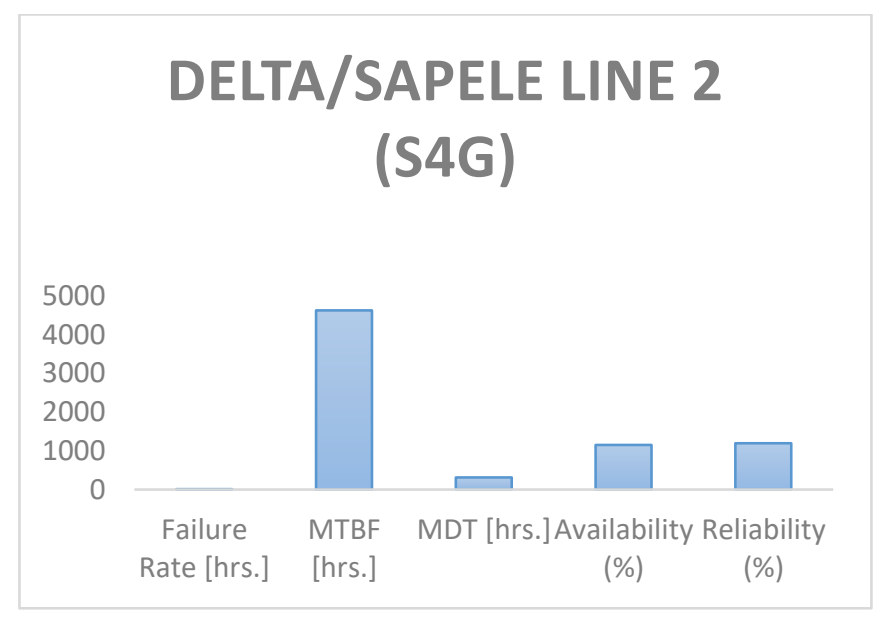

Fig. 13: Reliability Indices for S4G 
Failure Rate

A high value of failure rate is indicative of low reliability. It can be clearly seen that of the thirteen circuits, the Benin/Onitsha line 2 (B2T) has the least failure rate corresponding to about $0.03401 \mathrm{event} / \mathrm{hr}$. It was observed that the major causes of outage on this line is largely due to complete system collapse (cascaded failure) in the network as a result of under frequency operation caused by excessive load demand on the network with inadequate generation to meet this demand. Following closely to B2T is G3B with about 0.03401 event/hr. The Benin/Egbin line has the highest recorded failure rate within the study period. From observation, this line was frequently taken-out/opened on voltage control. There were recorded cases of voltages up to $368 \mathrm{kV}$.

\section{Mean Time Between Failures (MTBF)}

The longer the MTBF, the more reliable the system. B6N followed by $\mathrm{V} 7 \mathrm{H}$ has the shortest MBTF. This explains that the lines with short MTBF are more likely to fail often thereby reducing the overall system reliability. It is equally observed that B2T has the longest recorded MTBF for the study period.

\section{Mean Down Times (MDT)}

A high value of MDT indicates poor maintainability of the system. It was observed that $\mathrm{S} 4 \mathrm{~B}, \mathrm{~S} 4 \mathrm{G}, \mathrm{B} 11 \mathrm{~J}$ and $\mathrm{B} 6 \mathrm{~N}$ has the highest value of MDT in the order listed. This is to say when these line fails it takes a longer time to be restored to service. This is indicative of poor maintainability.

\section{Availability}

B6N has the least value followed by S4B, S4G and B11J. This implies high unavailability of these circuits/lines to perform their designated function within the study period. G3B, B2T, S3B, V7B, B12J, S5B, B5M, V7H and B1T with high value were in a state of operational effectiveness for within the study period.

\section{CONCLUSION}

The reliability analysis of a power system not only provides numerical indices for the effect of random component failures on the system, it can also act as a method of ranking the performance of power system designs or reinforcements. In this work, we have presented the reliability analysis of the $330 \mathrm{kV}$ lines in Benin sub - region. The reliability of any system is highly dependent on the reliability of its component parts.
We have been able to evaluate the reliability indices for the thirteen circuits and the results reveals the weakness of the system in the frequent failures that occurred on B6N, B11J, V7B, V7H, S4B and B1T and the poor maintenance of S4B, $\mathrm{S} 4 \mathrm{G}, \mathrm{B} 11 \mathrm{~J}$ and $\mathrm{B} 6 \mathrm{~N}$.

\section{RECOMMENDATIONS}

Since no system is designed to function forever, and since there are environmental factors always affecting its behavior, measures should always be put in place to improve the reliability of power supply. In order to increase the reliability on the transmission line in Benin sub-region, the following recommendations are presented:

- Improved maintenance on the following lines: Sapele/Delta line (S4G), Sapele/Benin line 2 (S4B), Benin/Ajaokuta line 1 (B11J) and Benin/Egbin line (B6N).

- $\quad$ Find an alternative means of evacuating power from Egbin power station. This could be achieved by making Benin/Egbin

Line a twin circuit with the same transmission capacity (redundancy).

- $\quad$ The transmission network should be reinforced to meet the N-1 criteria to avoid cascaded failures.

\section{REFERENCES}

[1] V. Alain, 'Reliability, Availability, Maintainability and Safety Assessment: Volume 1- Methods and Techniques, Wiley \&sons, 1992.

[2] Electric Power Research Institute (EPRI) White Paper, 'Integrating Smart Distributed Energy Resources with Distribution Management Systems", available online at https://www.epri.com, September 2012.

[3] J.J Popoola, A.A Ponnle and T.O Ale, "Reliability worth Assessment of Electric Power Utility in Nigerian Residential Customer Survey Results." AU Journal, vol. 14, Issue 3, Jan 2011.

[4] T. Gouen, "Electric Power Transmission System Engineering”, John Wiley, New York, USA, 1998.

[5] W. Zhang, "Reliability Evaluation of Bulk Power Systems Using Analytical and Equivalent Approaches", University of Saskatchewan, 1998.

[6] G. Nourbakhsh and G.M Stapleton, "Maintenance considerations in applied substation reliability assessment" International Conference on Probabilistic Methods Applied to Power Systems, Vancouver, Canada, pp. 391-395, 1997.

[7] J. Endrenyi, 'Reliability Modelling in Electric Power System", John Wiley \& Sons Ltd., New York, 1978. 